\title{
Mechanism of Interdigestive Migrating Motor Complex
}

\author{
Toku Takahashi
}

Department of Surgery, Medical College of Wisconsin and Zablocki VA Medical Center, Milwaukee, Wisconsin, USA

\begin{abstract}
Migrating motor complex (MMC) is well characterized by the appearance of gastrointestinal contractions in the interdigestive state. This review article discussed the mechanism of gastrointestinal MMC. Luminal administration of 5-hydroxytryptamine (5-HT) initiates duodenal phase II followed by gastrointestinal phase III with a concomitant increase of plasma motilin release in conscious dogs. Duodenal 5-HT concentration is increased during gastric phase II and phase III. Intravenous infusion of motilin increases luminal 5-HT content and induces gastrointestinal phase III. 5-HT antagonists significantly inhibits both of gastric and intestinal phase III, while $5-\mathrm{HT}_{3}$ antagonists inhibited only gastric phase III. These suggest that gastrointestinal MMC cycle is mediated via the interaction between motilin and 5-HT by the positive feedback mechanism. Gastric MMC is regulated via vagus, $5-\mathrm{HT}_{3 / 4}$ receptors and motilin, while intestinal $\mathrm{MMC}$ is regulated via intrinsic primary afferent neurons and $5-\mathrm{HT}_{4}$ receptors. Stress is highly associated with the pathogenesis of functional dyspepsia. Acoustic stress attenuates gastric phase III without affecting intestinal phase III in conscious dogs, via reduced vagal activity and increased sympathetic activity. It has been shown that subset of functional dyspepsia patients show reduced vagal activity and impaired gastric phase III. The physiological importance of gastric MMC is a mechanical and chemical cleansing of the empty stomach in preparation for the next meal. The impaired gastric MMC may aggravate dyspeptic symptoms following a food ingestion. Thus, maintaining gastric MMC in the interdigestive state is an important factor to prevent the postprandial dyspeptic symptoms.
\end{abstract}

(J Neurogastroenterol Motil 2012;18:246-257)

Key Words

Autonomic pathways; Enterochromaffin cell; Motilin; Serotonin

\section{Introduction}

Gastric motility in the fasted state is a cyclical phenomenon called the migrating motor complex (MMC). In a normal MMC cycle in humans and dogs, there are four phases. Phase I is a quiescent period with virtually no contractions. Phase II consists of intermittent, irregular low-amplitude contractions. Phase
III consists of short burst of regular high-amplitude contractions. Phase IV represents a short transition period back to the quiescence of phase I. ${ }^{1}$ Phase III contractions periodically occur every 90-120 minutes in humans and dogs.

Plasma motilin level is highly associated with the appearance of gastric phase III in humans and dogs. Plasma motilin levels vary in a cyclic fashion and its peaks regularly occur every 90-100 minutes during the period of gastric phase III in $\operatorname{dogs}^{2,3}$ and

Received: March 27, 2012 Revised: May 13, 2012 Accepted: May 23, 2012

(c) This is an Open Access article distributed under the terms of the Creative Commons Attribution Non-Commercial License (http://creativecommons. org/licenses/by-nc/3.0) which permits unrestricted non-commercial use, distribution, and reproduction in any medium, provided the original work is properly cited.

*Correspondence: Toku Takahashi, MD, PhD Department of Surgery, Medical College of Wisconsin and Zablocki VA Medical Center, Research Service 151, Zablocki VA Medical Center, 5000 West National Avenue, Milwaukee, WI 53295, USA

Tel: +1-414-384-2000 (ext. 41472),Fax: +1-414-382-5374, E-mail: ttakahashi@mcw.edu

Financial support: None.

Conflicts of interest: None. 
humans. ${ }^{4,5}$ Motilin administration causes gastric phase III contractions in dogs ${ }^{2,6}$ and humans.

In 1999, ghrelin was discovered as the endogenous ligand for the growth hormone secretagogue receptor (GHS-R) from rat stomach. ${ }^{7}$ Because of a structural resemblance to motilin, ghrelin is known as a motilin-related peptide. ${ }^{8,9}$ Phase III-like contractions are observed every $12-15$ minutes in rats ${ }^{10,11}$ and mice. ${ }^{12}$ As it is rather difficult to distinguish 3 phases in rats and mice, these phases are called as phase I-like contractions and phase III-like contractions in rats and mice. ${ }^{10,12}$ Ghrelin administration elicits phase III-like contractions of the stomach in rats ${ }^{10,13}$ and mice. ${ }^{12}$ Plasma ghrelin levels were highly associated with the occurrence of phase III-like contractions of the rat stomach. Spontaneous phase III-like contractions of the antrum were abolished by a GHS-R antagonist. ${ }^{13}$ These suggest that the spontaneous phase III-like contractions of the antrum are mediated via endogenously released ghrelin in rats. ${ }^{13}$

In contrast, ghrelin failed to cause any phase III contractions of the dog stomach. ${ }^{14}$ Although ghrelin has a structural resemblance to motilin, motilin administration failed to affect gastric emptying and GI transit in rats. ${ }^{15}$ Moreover, motilin and motilin receptor have not been found in rats. ${ }^{15}$ It seems that action of ghrelin and motilin in mediating interdigestive gastric contractions are different to some extent among humans, dogs and rodents. It is well established that motilin regulates gastric phase III contractions in dogs and humans, while ghrelin regulates gastric phase III-like contractions in rats and mice.

This review article focused on the mechanism of gastrointestinal MMC associated with motilin in humans and dogs. The mechanism of MMC still remains unclear and several serious questions have been raised.

\section{Questions About the Mechanism of Gas- trointestinal Migrating Motor Complex-}

\section{Mechanism of Motilin Release}

The duodenum, which stores motilin, plays an important role to initiate gastric MMC in dogs and humans. Motilin-immunoreactive cells are concentrated in the deeper portion of the crypt of the human and dog intestine. They are most frequent in the duodenal and jejunal mucosa; a few of them are also seen in the ileal mucosa. No motilin cells are found in the stomach, colon, and rectum. ${ }^{16}$

After duodenectomy, no obvious phase III contractions are seen in the gastric antrum. The plasma motilin concentration does not fluctuate as it does in normal dogs, and remains low after duodenectomy. The contractile response of the stomach to exogenous motilin after duodenectomy is similar to that of intact dogs. ${ }^{17}$ These indicate that released motilin from the duodenal mucosa and upper jejunum mediate gastric phase III.

The presence of nutrient in the duodenum strongly suppresses the endogenous release of motilin in a digestive state. In an interdigestive state, luminal acidification and bile are important factors in regulating motilin release from the duodenal mucosa. ${ }^{18}$ Atropine or hexamethonium blocks a cyclic increase in the plasma motilin concentration. Carbachol-induced motilin release is blocked by atropine, but not by hexamethonium. ${ }^{19}$ The existence of muscarinic receptors is demonstrated in motilin producing cells. ${ }^{20}$ Muscarinic type 3 receptors are responsible for motilin release from motilin-producing cells in perifusion system of the canine duodenum. ${ }^{21}$

It has been shown that the cyclical increments of pancreatic polypeptide and gastrin are both dependent on excitatory vagal innervation. However, participation of vagal control in the release of motilin has been controversial. Electrical stimulation of the vagus results in a significant increase in the plasma motilin concentration in anesthetized dogs. ${ }^{19,22,23}$ On the other hand, others demonstrated that truncal vagotomy did not influence the intermittent fluctuation or concentration of plasma motilin in the fasting state. ${ }^{24}$ This is further supported by an acute experiment showing that the spontaneous fluctuations in the plasma motilin concentration were not influenced by vago-sympathetic nerve blockade. ${ }^{3}$ Although the precise mechanism of motilin release still remains unclear, the release of motilin is likely to be controlled by non-vagal cholinergic innervation in normal conditions. $^{3,25}$

It is well known that intravenous-infusion of motilin induces gastric phase III. ${ }^{1}$ It is also known that exogenous motilin can stimulate the endogenous motilin release. ${ }^{26}$ The peak of plasma motilin level is observed during the late phase of gastric phase III or after finishing gastric phase III. ${ }^{27}$ Thus, Sarna et $\mathrm{al}^{28}$ proposed the possibility that endogenous motilin did not initiate spontaneous phase III. Instead, phase III contractions released motilin. They suggested that a positive feedback mechanism might exist because phase III contractions released motilin and that motilin, in turn, potentiated contractions. ${ }^{28}$ 


\section{Question No.1: Is Released Motilin Cause or Effect of Gastric Phase III?}

\section{Site of action of motilin}

Motilin receptors are present in the myenteric plexus, mucosa and muscle cells of gastrointestinal tract. ${ }^{29}$ These receptors may mediate its pharmacological as well as physiological actions. However, it has not been well established whether motilin acts through intrinsic neurons, ${ }^{30}$ extrinsic neurons ${ }^{25}$ or smooth muscles. $^{31}$ Motilin induced contractions were not inhibited by tetrodotoxin of the rabbit antrum in vitro, ${ }^{31}$ suggesting the direct action on the smooth muscle cells. In contrast, others demonstrated that atropine and hexamethonium attenuate motilin-induced contractions of the isolated stomach. ${ }^{30}$ This suggests that intramural cholinergic pathway is involved in mediating motilin-induced contractions of the dog stomach in vitro.

Ex vivo isolated stomach does not show cyclic MMC pattern and motilin-induced contractions are much less potent than that of in vivo. ${ }^{30}$ Gastric phase III, but not intestinal phase III, is abolished by blockade of the cervical vago-sympathetic nerve trunk in conscious dogs in vivo. ${ }^{3}$ As sympathetic receptor blockers do not affect the inhibitory effect of vagal blockade, ${ }^{32}$ gastric phase III seems to be regulated by vagus nerve. Spontaneous phase III contractions after vagotomy are also less potent than that of be-

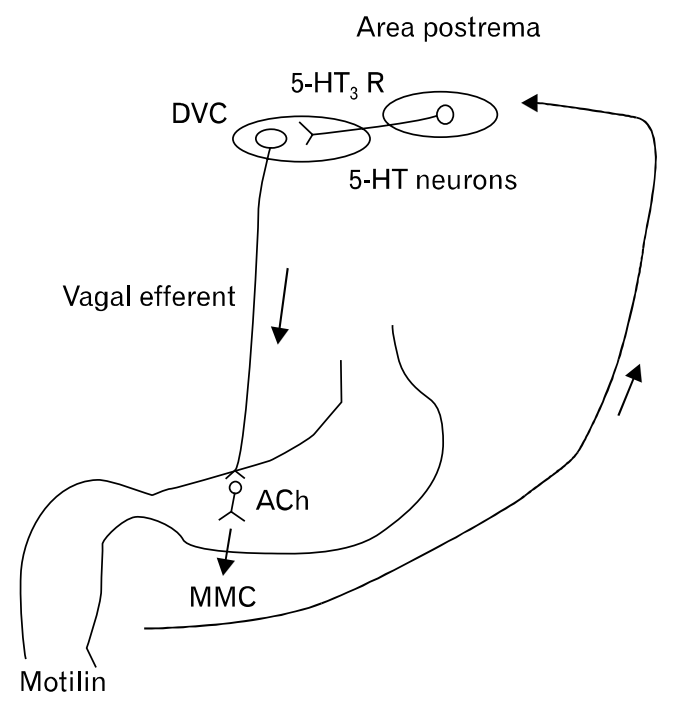

Figure 1. Suggested mechanism of motilin-induced gastric migrating motor complex by Dr. Itoh. ${ }^{25}$ Released motilin from the duodenal mucosa reaches at the area postrema and activates 5-hydroxytryptamine (5-HT) neurons at the dorsal vagal complex. Stimulation of 5-HT neurons activates vagal efferents through $5-\mathrm{HT}_{3}$ receptors. DVC, dorsal vagal complex; $\mathrm{ACh}$, acetylcholine; MMC, migrating motor complex. fore vagotomy. ${ }^{33}$ Therefore, it is generally accepted that motilin-induced gastric phase III is vagal dependent in a physiological condition. ${ }^{25}$

Motilin-induced phase III of the stomach is antagonized by the systemic treatment with 5-hydroxytryptamine $3\left(5-\mathrm{HT}_{3}\right)$ receptor antagonists in dogs ${ }^{34,35}$ and humans. ${ }^{36}$ Spontaneous gastric phase III, but not intestinal phase III, is also antagonized by $5-\mathrm{HT}_{3}$ antagonists. ${ }^{34,35}$ These suggest that gastric phase III is mediated via an endogenous release of 5-HT.

The area postrema is very rich in fenestrated capillaries, and also supplied with numerous neurons including 5-HT neurons in the perivascular spaces around the capillaries and linked to the dorsal vagal complex. ${ }^{37}$ Based on this evidence, Itoh $^{25}$ previously proposed the possibility that motilin may stimulate motilin receptors of 5-HT neurons in the area postrema. Stimulation of 5-HT neurons by motilin activates vagal efferents through $5-\mathrm{HT}_{3}$ receptors, resulting in gastric phase III (Fig. 1). However, the existence of motilin receptors has not been demonstrated in the area postrema. Question No.2: Where Are Motilin Receptors Lo-
cated Which Mediate Gastric Phase III?

\section{Question No.3: What Is the Relationship Bet- ween Motilin and 5-Hydroxytryptamine?}

\section{Question No.4: Where Are 5-Hydroxytryptamine 3 Receptors Located Which Mediate Motilin-in- duced Gastric Phase III?}

Different mechanism between gastric migrating motor complex and intestinal migrating motor complex

Gastric MMC and intestinal MMC are thought to be controlled by different mechanisms. Although plasma motilin level is highly associated with the appearance of gastric phase III, ${ }^{1}$ phase III contractions in the small intestine sometimes occur without a concomitant increase in plasma motilin concentration. ${ }^{38}$ Motilin antiserum inhibits the occurrence of phase III contractions only in the stomach, and not in the intestine. ${ }^{39}$ After duodenectomy, no obvious phase III contractions are seen in the gastric antrum, but migrating phase III contractions are seen in the upper jejunum. ${ }^{17}$ Chronic vagotomy reduces gastric phase III contractions without affecting the intestinal phase III contractions. ${ }^{33}$ These suggest that vagal innervation regulates gastric $\mathrm{MMC}$, but not intestinal MMC.

As mentioned above, it seems that gastric $\mathrm{MMC}$ is mediated 
via motilin, vagal pathway and $5-\mathrm{HT}_{3}$ receptors. In contrast, intestinal MMC is not antagonized by $5-\mathrm{HT}_{3}$ antagonists. ${ }^{34,35}$

\section{Question No.5: What Is the Mediator of Intes- tinal Migrating Motor Complex?}

When we carefully check gastrointestinal MMC recordings in dogs, it is obvious that duodenal phase III is frequently antecedent to gastric phase III. ${ }^{1,40-42}$ However, no reasonable explanation has been shown.

\section{Question No.6: What Is the Relationship Between Duodenal Phase III and Gastric Phase III?}

\section{Mystery of gastrointestinal migrating motor complex}

It has been a mystery how gastrointestinal MMC is regulated periodically every 90-120 minutes. It has been demonstrated that exogenous motilin stimulates endogenous release of motilin. ${ }^{26}$ This suggests a positive feedback mechanism is likely to operate when the plasma motilin concentration increases during the interdigestive state. Accordingly, an inhibitory mechanism should be present to break the positive feedback system; otherwise, endogenous release of motilin will continue.

\section{Question No.7: What Is the Initial Stimulator and Terminator of Gastric Phase III?}

\section{Possible Mechanisms of Mediating Gastro- intestinal Migrating Motor Complex}

\section{Luminal Release of 5-Hydroxytryptamine}

A 5-HT in the gastrointestinal tract is involved in regulating its motility. A 5-HT stimulates phase II-like contractions when administered during phase I of the canine small intestine. ${ }^{43}$ In humans, 5-HT re-uptake inhibitor (paroxetine) shortens MMC cycle and increases the propagation velocity of intestinal phase III. $^{44}$ This suggests that endogenous 5 -HT plays an important role to regulate intestinal MMC in humans.

While 5-HT acts as a neurotransmitter of the enteric nervous system, ${ }^{45}$ the majority of 5 -HT is stored in enterochromaffin (EC) cells of epithelial cells. EC cells have been considered to release 5-HT mainly into the blood vessels and/or intrinsic nerve terminal via a basolateral border. ${ }^{46}$ In contrast, others showed that 5-HT was also released into the intestinal lumen. ${ }^{47-50}$ Electrical stimulation of the vagus nerves or duodenal acidification evokes 5-HT release from EC cells into the intestinal lumen in concen- trations as high as $1.9 \mu \mathrm{M}^{49,51,52}$ A 5-HT is released into the lumen, but not into the portal circulation, in response to luminal pressure increase of the rat colon. ${ }^{53}$

Immunoelectron microscopic study showed the anatomical evidence that 5 -HT is released from EC cells in response to increase of luminal pressure of the rat duodenum. ${ }^{54}$ Aggregation of secretory granules of 5-HT is located in the apical as well as basolateral cytoplasm of EC cells in basal conditions. After the increase of intraluminal pressure, an increase of empty 5-HT granules and swelling of secretory 5-HT granules are observed at the apical cytoplasm. Many secretory 5-HT granules are no longer dense and 5-HT particles are scattered over the apical cytoplasmic matrix and microvilli. ${ }^{54}$ This indicates that 5 - $\mathrm{HT}$ is primarily stored in the secretory granules of EC cells. In response to intraluminal pressure increase, 5-HT particles are released into the extra-granular cytoplasmic matrix. Thus, 5-HT particles diffuse or are transported into the duodenal lumen through the apical cell membrane. $^{54}$

Luminally applied 5-HT can move by passive diffusion across the intestinal wall of the guinea pig ileum. ${ }^{55}$ A 5-HT can cross the intestinal wall from the mucosa to the serosa (apical-tobasolateral direction). ${ }^{56}$ Thus, 5 -HT into the intestinal lumen could reach the synaptic circuitry resulting in stimulation of 5-HT receptors located on the lamina propria and/or enteric nervous system. Luminally released 5-HT from EC cells stimulates $5-\mathrm{HT}_{3}$ receptors located on the vagal sensory fibers. Through the brain stem (nucleus tractus solitarius and dorsal motor nucleus of the vagus $[\mathrm{DMV}])$, the sensory information is transferred and the vagal efferent stimulates the release of acetylcholine from the myenteric plexus, resulting in muscle contraction. ${ }^{57}$ A 5-HT also activates enteric afferent neurons to stimulate intestinal motor function. ${ }^{58-60}$

Luminally administered 5-HT initiates duodenal phase II followed by gastric phase III with the concomitant increase of plasma motilin levels in conscious dogs. ${ }^{61}$ During duodenal phase II, luminal content of 5 -HT of the duodenum is increased from 29 to $59 \mathrm{ng} / \mathrm{mL}$. Luminal content of 5 -HT of the duodenum is further increased to $250 \mathrm{ng} / \mathrm{mL}$ during gastric phase III. In contrast, the luminal concentration of 5-HT of the stomach does not significantly change during phase I, II and III (Fig. 2). This suggests that luminal concentration of 5-HT of the duodenum, but not the stomach, may play an important role to regulate gastrointestinal MMC.

The changes of the duodenal pressure are observed during gastrointestinal phase I. Luminal pressure of the duodenum in- 


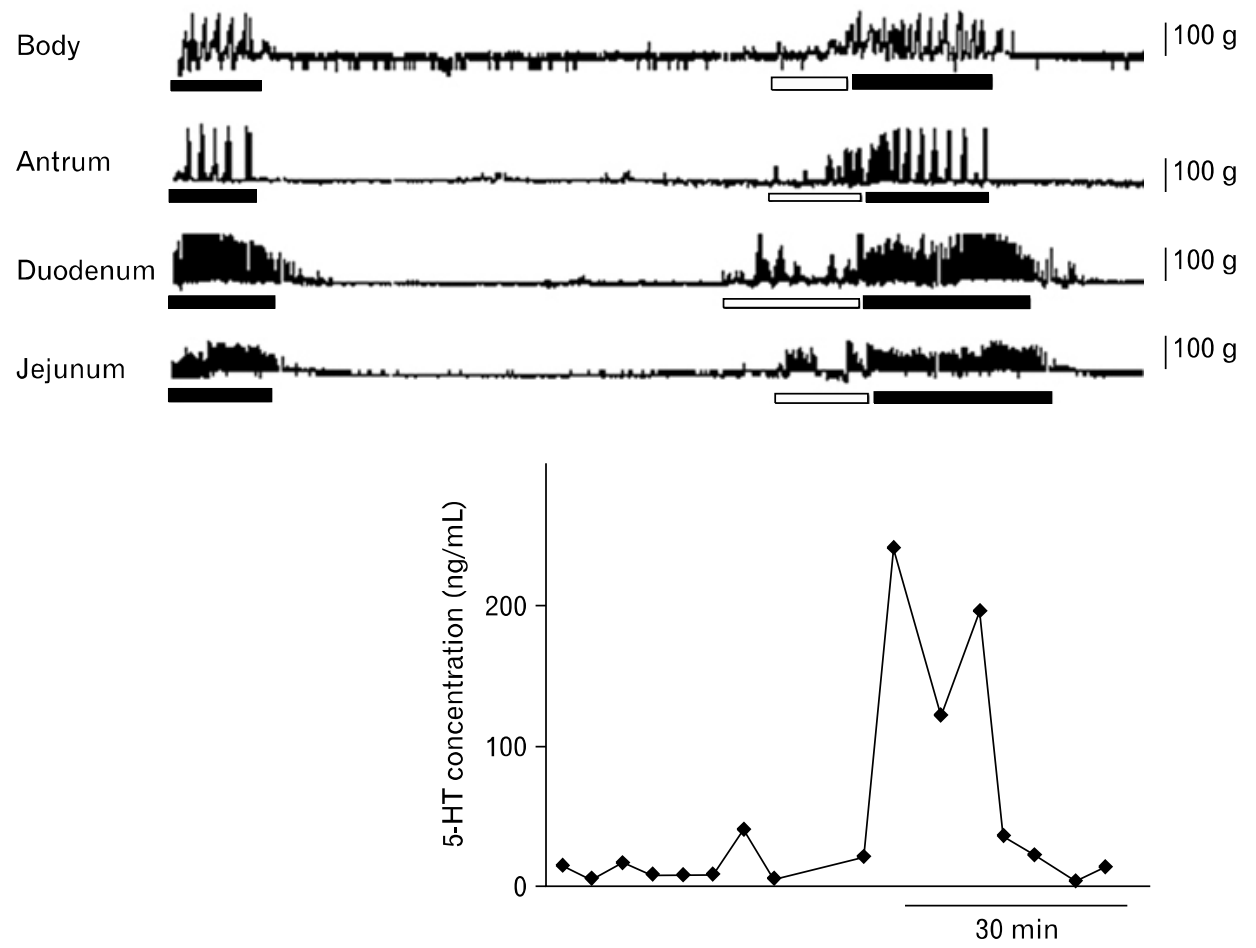

Figure 2. Luminal concentration of 5-hydroxytryptamine (5-HT) of the duodenum during migrating motor complex cycle. During duodenal phase I, the luminal concentration of $5-\mathrm{HT}$ of the duodenum is $29 \mathrm{ng} / \mathrm{mL}$, which is significantly increased to $59 \mathrm{ng} / \mathrm{mL}$ during the duodenal phase II. Luminal concentration of $5-\mathrm{HT}$ of the duodenum is further increased to $250 \mathrm{ng} / \mathrm{mL}$ during phase III. In contrast to the duodenum, luminal concentration of $5-\mathrm{HT}$ of the stomach is not significantly changed during phase I, II and III. Open squares indicate phase II contractions and closed squares indicate phase III contractions. Adapted from Nakajima et al. ${ }^{61}$

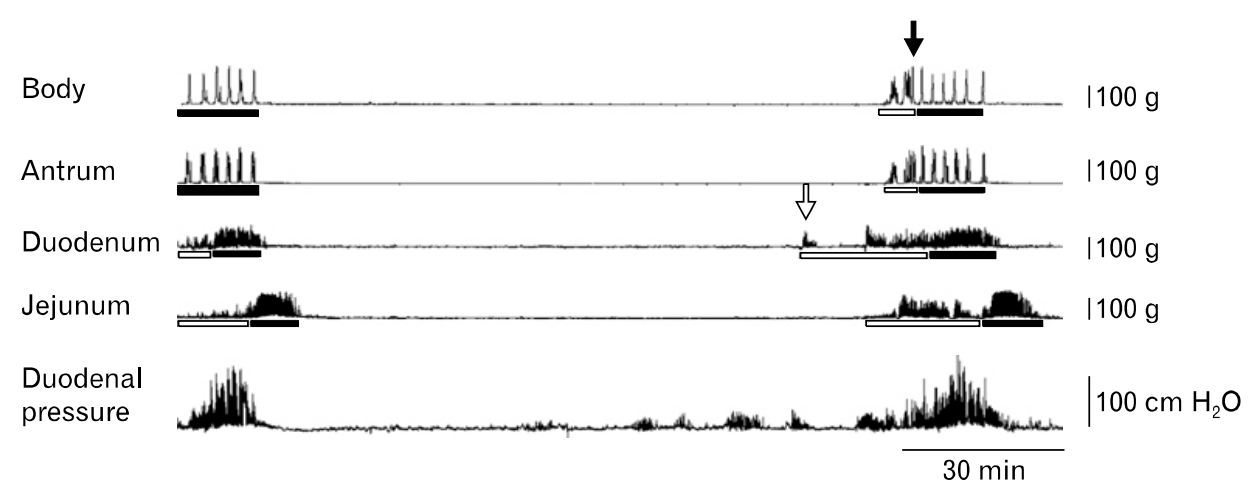

Figure 3. Simultaneous recording of gastrointestinal migrating motor complex and duodenal pressure. During phase I, duodenal pressure changes are observed. Luminal pressure of the duodenum increases by $20-30 \mathrm{H}_{2} \mathrm{O}$, just before the occurrence of duodenal phase II and III (an open arrow). Duodenal phase II (an open arrow) is followed by gastric phase III (a solid arrow). Open squares indicate phase II contractions and closed squares indicate phase III contractions. Adapted from Nakajima et al. ${ }^{61}$

creases by $20-30 \mathrm{~cm} \mathrm{H}_{2} \mathrm{O}$, just before the occurrence of duodenal phase II. Duodenal phase II is followed by gastric phase II and III. The spontaneous duodenal phase II is always antecedent to the spontaneous gastric phase II (Fig. 3) ${ }^{61}$

\section{Site of Action of Motilin}

As mentioned above, it is highly likely that motilin-induced gastric phase III is mediated via vagal cholinergic pathways and $5-\mathrm{HT}_{3}$ receptors. Motilin released in the villi of the duodenum enters the capillaries on the one hand, and may possibly stimulate nerve terminals in the villi on the other. However, no motilin receptors have been documented in the vagus nerve or nodose ganglion. In contrast, $5-\mathrm{HT}_{3}$ receptors are located on the nerve terminal of vagal afferent of the duodenal mucosa. Fibers immunoreactive for $5-\mathrm{HT}_{3}$ receptors in the duodenal mucosa are markedly reduced by subdiaphragmatic vagotomy or chemical denervation of vagal afferents. ${ }^{62}$ Thus, nerve endings may well be the targets for the 5-HT released from EC cells. ${ }^{63}$ 
A

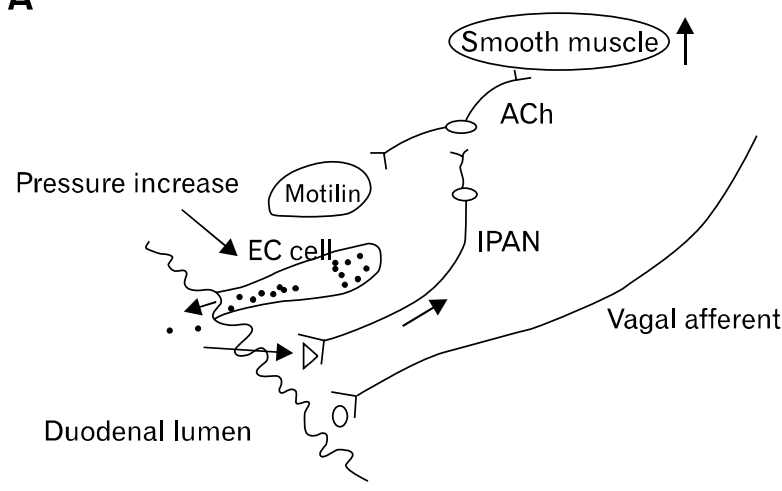

Plasma motilin

Stomach

Duodenum

Luminal 5-HT

B

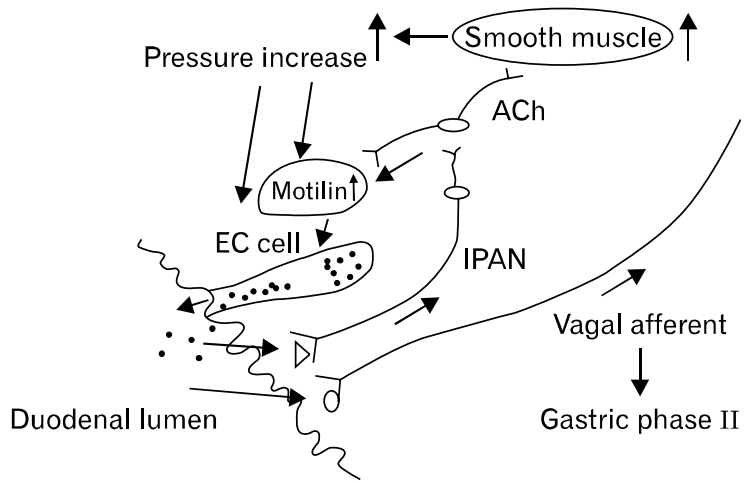

C

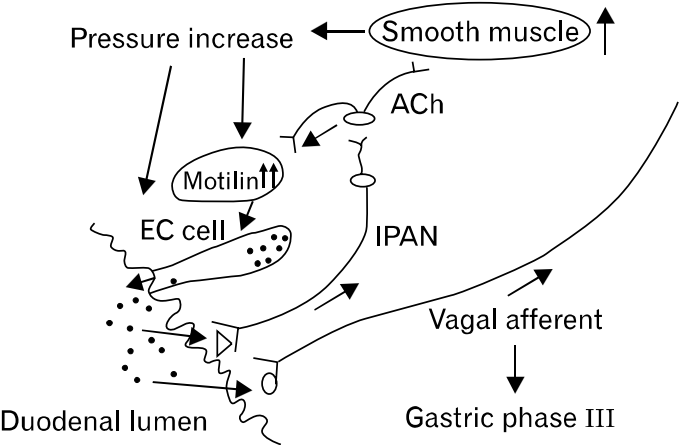

Motilin receptor are expressed in the muscle and mucosa of the human gastrointestinal tract. ${ }^{29}$ Exogenously applied motilin stimulates 5-HT release into the lumen of the duodenum in conscious dogs. ${ }^{61,64}$ In vitro study also showed that motilin stimulated 5-HT release into the lumen of the canine jejunum. ${ }^{65}$ These findings raise the possibility that motilin initiates gastrointestinal phase III through the release of mucosal 5-HT from the duodenum.

It is conceivable that released motilin from the duodenal mucosa stimulates the release of 5-HT from the duodenal EC cells. Released 5-HT activates $5-\mathrm{HT}_{3}$ receptors of the vagal afferent
Figure 4. Possible mechanism of gastrointestinal migrating motor complex during gastric phase I (A), phase II (B) and phase III (C). During gastic phase I, the basal secretion of gastric, pancreatic and biliary juices gradually increases the luminal pressure of the duodenum $(A)$, resulting in 5-hydroxytryptamine (5-HT) release from Plasma motilin enterochromaffin cells. Released 5-HT Stomach initiates duodenal phase II via $5-\mathrm{HT}_{4}$ Duodenum receptors of intrinsic primary afferent Luminal 5-HT neurons (IPAN) (A). Duodenal phase II causes further increase of duodenal pressure, which stimulates more 5-HT release. This positive circuit (pressure increase and 5-HT release) gradually enhances the amplitude of duodenal phase II, leading to duodenal phase III. Finally, maximally increased duodenal pressure stimulates motilin release (B). Released motilin stimulates large amounts of 5-HT release which acts on $5-\mathrm{HT}_{3}$ receptors of vagal afferent, in addition to $5-\mathrm{HT}_{4}$ receptors of IPAN. Released motilin induces gastric phase III via vago-vagal reflex $^{61}(\mathrm{C})$. Black dots indicate 5-HT granules/particles. Open triangle indicates $5-\mathrm{HT}_{4}$ receptors and open circle indicates 5- $\mathrm{HT}_{3}$ receptors. $\mathrm{ACh}$, acetylcholine; $\mathrm{EC}$ cell, enterochromaffin cell.

(Fig. 4). The sensory information is carried to the brain stem (nucleus tractus solitarius and DMV) and activates vagal efferent. Finally, motilin initiates gastric phase III via vago-vagal reflex (Fig. 5). ${ }^{61}$

\section{Relationship Between Gastric Migrating Motor Complex and Intestinal Migrating Motor Complex}

A 5-HT stimulates phase II-like contractions when administered during phase I of the canine small intestine. Endogenous 5-HT affects motor activity during phase II and III and appears to be a candidate regulator of the intrinsic mechanisms gov- 


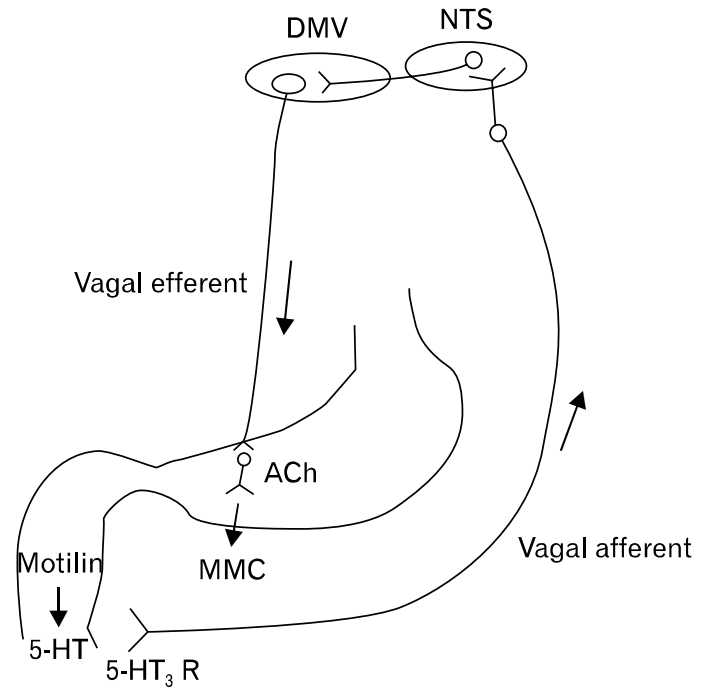

Figure 5. Possible mechanism of gastric migrating motor complex. Released motilin from the duodenal mucosa stimulates the release of 5-hydroxytryptamine (5-HT) from the duodenal enterochromaffin cells. Released 5-HT activates $5-\mathrm{HT}_{3}$ receptors of the vagal afferent. The sensory information is carried to the brain stem (nucleus tractus solitarius and dorsal motor nucleus of the vagus) and activates vagal efferent. Finally, motilin initiates gastric phase III via vago-vagal reflex. DMV, dorsal motor nucleus of the vagus; NTS, nucleus tractus solitarius; ACh, acetylcholine; MMC, migrating motor complex.

erning the initiation and propagation of the intestinal MMC. ${ }^{43}$

Previous study showed that intraluminal administration of 5 -HT $\left(10^{-5} \mathrm{M}\right)$ into the duodenum caused phasic contractions in dogs. ${ }^{66}$ Intra-duodenal administration of 5 -HT $\left(10^{-7} \mathrm{M}\right)$ initiated duodenal phase II in conscious dogs. 5-HT $\left(10^{-7} \mathrm{M}\right)$-induced duodenal phase II contractions migrated to the jejunum. In contrast, 10 times higher concentration of 5-HT $\left(10^{-6} \mathrm{M}\right)$ initiated duodenal phase II followed by gastric phase II/III and plasma motilin release. ${ }^{61}$ This raises the possibility that $5-\mathrm{HT}_{4}$ receptors of intrinsic primary afferent neurons (IPAN) are 10 times more sensitive than $5-\mathrm{HT}_{3}$ receptors of the vagal afferent in the canine duodenum.

Gastric MMC is inhibited by a $5-\mathrm{HT}_{3}$ receptor antagonist (ondansetron), while intestinal MMC is not affected by ondansetron. On the other hand, intestinal MMC as well as gastric MMC is significantly attenuated by a $5-\mathrm{HT}_{4}$ receptor antagonist (GR 125,487). ${ }^{61}$ This suggests that intestinal MMC is regulated by $5-\mathrm{HT}_{4}$ receptors, while gastric $\mathrm{MMC}$ is regulated by $5-\mathrm{HT}_{3}$ receptors and $5-\mathrm{HT}_{4}$ receptors.

Pancreatic and biliary secretion into the duodenum is observed in the period of duodenal phase I in conscious dogs. ${ }^{67,68} \mathrm{It}$ is conceivable that the basal secretion of gastric, pancreatic and biliary juices gradually increases the luminal pressure of the duodenum during phase I, which may stimulate 5-HT release from EC cells. Released 5-HT initiates duodenal phase II via 5- $\mathrm{HT}_{4}$ receptors of IPAN. Thus, the initiation of duodenal phase II is not due to the increase of plasma motilin release.

Duodenal phase II causes increase of duodenal pressure, which further stimulates the release of 5-HT. This positive circuit (pressure increase and 5-HT release) gradually enhances the amplitude of duodenal phase II, leading to duodenal phase III. Finally, maximally increased duodenal pressure stimulates motilin release (Fig. 4).

\section{Possible Answers to Question No.1-7}

\section{Question No.1: Is Released Motilin Cause or Effect of Gastric Phase III?}

Answer is both. Motilin stimulates gastric phase III. Released 5-HT induced by duodenal contractions stimulates motilin release.

\section{Question No.2: Where Are Motilin Receptors Lo- cated Which Mediate Gastric Phase III?}

It is likely that motilin receptors are located at EC cells of the duodenal mucosa, which mediate gastric phase III.

\section{Question No.3: What Is the Relationship Between Motilin and 5-Hydroxytryptamine?}

Luminal 5-HT stimulates duodenal contractions, resulting in luminal pressure increase. Increased luminal pressure initiates motilin release. Released motilin stimulates 5 -HT release by a positive feedback mechanism, as previously suggested by Sarna et al. ${ }^{28}$

\section{Question No.4: Where Are 5-Hydroxytryptamine 3 Receptors Located Which Mediate Motilin-in- duced Gastric Migrating Motor Complex?}

A $5-\mathrm{HT}_{3}$ receptors are located on vagal afferents, which indirectly mediate motilin-induced gastric MMC.

\section{Question No.5: What Is the Mediator of Intesti- nal Migrating Motor Complex?}

Intestinal $\mathrm{MMC}$ is regulated by $5-\mathrm{HT}_{4}$ receptors of IPAN. 


\section{Question No.6: What Is the Relationship Between Duodenal Phase III and Gastric Phase III?}

Duodenal phase II and III can stimulate motilin release via increasing intraluminal pressure of duodenum. Released motilin can stimulate gastric phase II and III.

\section{Quesgtion No.7: What Is the Initial Stimulator and Terminator of Gastric Phase III?}

Initial stimulator is released $5-\mathrm{H}$ in response to intraluminal pressure increase during duodenal phase II. Maximally increased duodenal pressure stimulates motilin release from the duodenal mucosa. Released motilin further stimulates 5 -HT release by a positive feedback mechanism. A large amount of 5-HT release stimulated by motilin acts on $5-\mathrm{HT}_{3}$ receptors of the duodenal vagal afferent, in addition to $5-\mathrm{HT}_{4}$ receptors of duodenal IPAN (Fig. 4).

Therefore, released motilin induces gastric phase II and III via vagal dependent mechanisms. This may be the reason why duodenal phase II contractions are antecedent to gastric phase II contractions. In contrast, motilin infusion did not elicit antecedent duodenal phase II contractions prior to the gastric phase
II contractions. ${ }^{61}$ This suggests that motilin initiates gastric phase II contractions, but not duodenal phase II contractions.

A positive feedback mechanism is likely to operate when the plasma motilin concentration increases during the interdigestive state. Accordingly, an inhibitory mechanism should be present to break the positive feedback system. It still remains unknown how gastrointestinal MMC is terminated. As the luminal release of 5 -HT is the key factor to initiate gastrointestinal MMC, the terminator should be involved in mediating the inhibition of 5-HT release.

\section{Effects of Stress on Gastrointestinal Migra- ting Motor Complex}

Psychological stress plays a major role in functional gastrointestinal disorders, such as irritable bowel syndrome ${ }^{69}$ and functional dyspepsia (FD). ${ }^{70,71}$ Experimental studies demonstrated that colonic motility was stimulated, ${ }^{72-74}$ while gastric emptying was delayed by stress ${ }^{75,76}$ in rodents. The inhibitory effects of stress on gastric emptying were mediated via reduced parasympathetic pathways ${ }^{77,78}$ or increased sympathetic pathways ${ }^{76,79}$ in rodents.

A

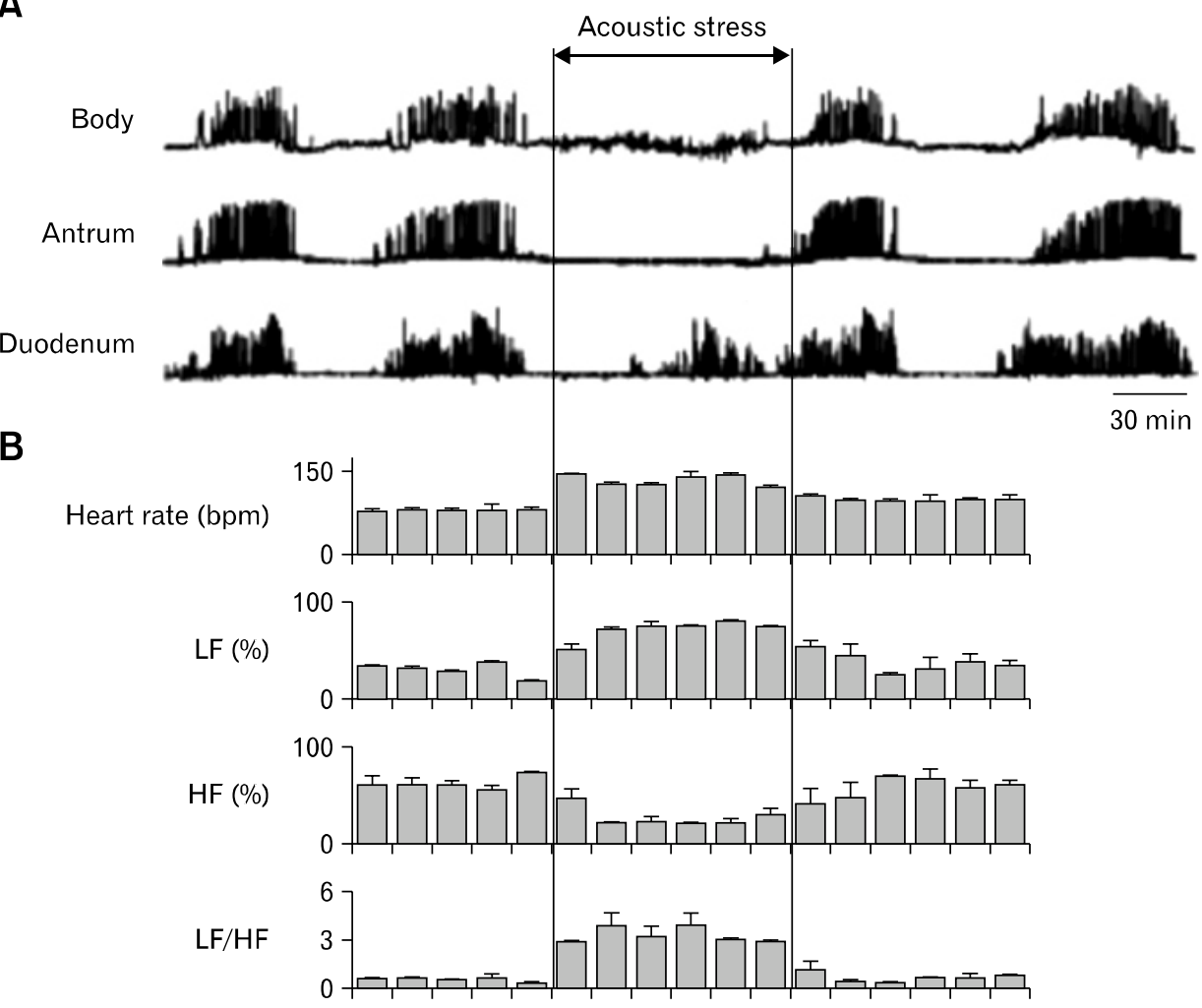

Figure 6. Effects of acoustic stress on gastrointestinal migrating motor complex (MMC) (A) and heart rate viability (B) in conscious dogs. Acoustic stress almost completely abolishes gastric MMC (body and antrum) without affecting intestinal MMC (duodenum). During acoustic stress loading, heart rate and sympathetic tone (low frequency component; LF) are increased, while parasympathetic tone (high frequency component; HF) is reduced. As a result, the ratio between sympathetic tone and parasympathetic tone $(\mathrm{LF} / \mathrm{HF})$ is increaed by acoustic stress. Adapted from Taniguchi et al. ${ }^{83}$ 
Acoustic stress forced to hear loud noise through earpieces in conscious dogs. Previous studies demonstrated that acoustic stress delayed the occurrence of the next gastric MMC. ${ }^{80-82}$ Acoustic stress attenuates gastric phase III without affecting intestinal phase III. ${ }^{83}$ In order to evaluate the function of autonomic nervous system in a conscious state, heart rate viability analysis has been widely used. During acoustic stress, heart rate and sympathetic tone (low frequency component) are increased, while parasympathetic tone (high frequency component) is reduced (Fig. 6). As gastric phase III, but not intestinal phase III, is regulated by vagal efferent, it is likely that the impaired gastric phase III induced by acoustic stress is mainly due to reduced vagal activity. ${ }^{83}$ Therefore, if we can improve reduced vagal activity associated stress, impaired gastric phase III would be treatable. It has been shown that somatosensory nerve stimulation restores impaired gastric phase III induced by acoustic stress in conscious dogs.

\section{Clinical Relevance of Gastrointestinal Migra- ting Motor Complex}

The physiological importance of gastric MMC is a mechanical and chemical cleansing of the empty stomach in preparation for the next meal. ${ }^{25}$ When gastric phase III activity is impaired, the gastric content may stay for a longer period. Impaired gastric phase III activity may cause retention of the gastric contents and bacterial overgrowth, resulting in various symptoms. Over 30 years ago, Vantrappen et al. proposed the possibility that bacterial overgrowth might be due to specific motility disorder, with namely a complete or almost complete absence of interdigestive MMC. ${ }^{84}$

Absence of phase III activity has been found in dyspeptic Helicobacter pylori-positive patients more frequently than in those without the infection. After $H$. pylori eradication, the incidence of gastrointestinal phase III was not altered. ${ }^{85,86}$ Thus, it is assumed that this abnormal motility might be a predisposing condition for bacterial colonization of the gastric mucosa rather than its consequence.

FD is a symptom complex characterized by postprandial upper abdominal discomfort or pain, early satiety, nausea, vomiting, abdominal distension, bloating, and anorexia in the absence of organic disease. Approximately 50\% of patients with FD have motor disorders, such as antral hypomotility, impaired accommodation reflex and gastric dysrhythmias. Studies using questionnaires showed that more than $75 \%$ of FD patients reported relationship between aggravation of symptoms and ingestion of meal. ${ }^{87}$

In the clinical setting, abnormal motility patterns of gastric MMC have been demonstrated. ${ }^{88}$ The incidence of gastric phase III activity of the antrum is significantly reduced in patients with FD, compared to that of healthy controls. ${ }^{89-91}$ The impaired and/or irregular gastric MMC may aggravate dyspeptic symptoms following food ingestion. Dyspeptic symptoms in the postprandial state would be reduced when impaired gastric MMC in the interdigestive state is improved. Subsets of FD patients show the reduced activity of the vagus. ${ }^{92,93}$ As vagus plays an important role to mediate gastric $\mathrm{MMC}$, impaired activity of the vagus may contribute to the impaired gastric MMC in FD patients.

\section{Conclusion}

Luminal administration of 5-HT initiates duodenal phase II followed by gastric phase III and intestinal phase III with a concomitant increase of plasma motilin release. Duodenal 5-HT concentration is significantly increased during phase II and phase III, compared to that of phase I. On the other hand, 5-HT content in the stomach is not significantly altered throughout the MMC cycle. Intravenous infusion of motilin increases luminal 5-HT content and induces gastric phase III and intestinal phase III. A 5- $\mathrm{HT}_{4}$ receptor antagonists inhibit both of gastric and intestinal phase III, while $5-\mathrm{HT}_{3}$ receptor antagonists inhibit only gastric phase III. These suggest that MMC cycle is mediated via the interaction between motilin and 5-HT by the positive feedback mechanism.

Acoustic stress attenuates gastric phase III without affecting intestinal phase III in conscious dogs.

The impaired gastric phase III induced by stress is mediated via reduced vagal activity and increased sympathetic activity. Stress is highly associated with the pathogenesis of FD. It has been shown that subset of FD patients shows reduced activity of the vagus and that the incidence of gastric phase III is reduced in these patients. The impaired gastric MMC may aggravate dyspeptic symptoms following food ingestion. Thus, it is proposed that maintaining gastric $\mathrm{MMC}$ in the interdigestive state is an important factor to prevent the postprandial dyspeptic symptoms.

\section{Acknowledgements}

The author greatly appreciate the late Zen Itoh for his valuable advise during the study. 


\section{References}

1. Itoh Z, Takeuchi S, Aizawa I, et al. Changes in plasma motilin concentration and gastrointestinal contractile activity in conscious dogs. Am J Dig Dis 1978;23:929-935.

2. Itoh $\mathrm{Z}$, Honda R, Hiwatashi $\mathrm{K}$, et al. Motilin-induced mechanical activity in the canine alimentary tract. Scand J Gastroenterol 1976; 39(suppl):93-110.

3. Hall KE, Greenberg GR, El-Sharkawy TY, Diamant NE. Vagal control of migrating motor complex-related peaks in canine plasma motilin, pancreatic polypeptide, and gastrin. Can J Physiol Pharmacol 1983;61:1289-1298.

4. Vantrappen G, Janssens J, Peeters TL, Bloom SR, Christofides ND, Hellemans J. Motilin and the interdigestive migrating motor complex in man. Dig Dis Sci 1979;24:497-500.

5. Janssens J, Vantrappen G, Peeters TL. The activity front of the migrating motor complex of the human stomach but not of the small intestine is motilin-dependent. Regul Pept 1983;6:363-369.

6. Wingate DL, Ruppin H, Green WE, et al. Motilin-induced electrical activity in the canine gastrointestinal tract. Scand J Gastroenterol 1976;39(suppl):111-118.

7. Kojima M, Hosoda H, Date Y, Nakazato M, Matsuo H, Kangawa $\mathrm{K}$. Ghrelin is a growth-hormone-releasing acylated peptide from stomach. Nature 1999;402:656-660.

8. Tomasetto C, Karam SM, Ribieras S, et al. Identification and characterization of a novel gastric peptide hormone: the motilin-related peptide. Gastroenterology 2000;119:395-405.

9. Asakawa A, Inui A, Kaga T, et al. Ghrelin is an appetite-stimulatory signal from stomach with structural resemblance to motilin. Gastroenterology 2001;120:337-345.

10. Fujino K, Inui A, Asakawa A, Kihara N, Fujimura M, Fujimiya M. Ghrelin induces fasted motor activity of the gastrointestinal tract in conscious fed rats. J Physiol 2003;550(Pt 1):227-240.

11. Tatewaki M, Harris M, Uemura K, et al. Dual effects of acupuncture on gastric motility in conscious rats. Am J Physiol Regul Integr Comp Physiol 2003;285:R862-R872.

12. Zheng J, Ariga $\mathrm{H}$, Taniguchi $\mathrm{H}$, Ludwig $\mathrm{K}$, Takahashi T. Ghrelin regulates gastric phase III-like contractions in freely moving conscious mice. Neurogastroenterol Motil 2009;21:78-84.

13. Ariga H, Tsukamoto K, Chen C, Mantyh C, Pappas TN, Takahashi T. Endogenous acyl ghrelin is involved in mediating spontaneous phase III-like contractions of the rat stomach. Neurogastroenterol Motil 2007;19:675-680.

14. Ohno T, Kamiyama Y, Aihara R, et al. Ghrelin does not stimulate gastrointestinal motility and gastric emptying: an experimental study of conscious dogs. Neurogastroenterol Motil 2006;18:129-135.

15. Depoortere I, De Winter B, Thijs T, De Man J, Pelckmans P, Peeters T. Comparison of the gastroprokinetic effects of ghrelin, GHRP-6 and motilin in rats in vivo and in vitro. Eur J Pharmacol 2005;515:160-168

16. Kobayashi S, Iwanaga T, Fujita T, Yanaihara N. Do enterochromaffin (EC) cells contain motilin? Arch Histol Jpn 1980;43:85-98.

17. Suzuki H, Mochiki E, Haga N, Shimura T, Itoh Z, Kuwano H. Effect of duodenectomy on gastric motility and gastric hormones in dogs. Ann Surg 2001;233:353-359.
18. Goll R, Nielsen SH, Holst JJ. Regulation of motilin release from isolated perfused pig duodenum. Digestion 1996;57:341-348.

19. Fox JE, Daniel EE, Jury J, Track NS, Chiu S. Cholinergic control mechanisms for immunoreactive motilin release and motility in the canine duodenum. Can J Physiol Pharmacol 1983;61:1042-1049.

20. Poitras P, Dumont A, Cuber JC, Trudel L. Cholinergic regulation of motilin release from isolated canine intestinal cells. Peptides 1993;14: 207-213.

21. Yamada T, Mizumoto A, Satoh M, Haga N, Itoh Z. Muscarinic control of phase III contractions and motilin release in dogs. Peptides 1997;18:673-680.

22. Lee KY, Park HJ, Chang TM, Chey WY. Cholinergic role on release and action of motilin. Peptides 1983;4:375-380.

23. Lee KY, Chang TM, Chey WY. Effect of electrical stimulation of the vagus on plasma motilin concentration in dog. Life Sci 1981;29: 1093-1097.

24. Yoshiya $\mathrm{K}$, Yamamura T, Ishikawa $\mathrm{Y}$, et al. The failure of truncal vagotomy to affect motilin release in dogs. J Surg Res 1985;38:263-266.

25. Itoh Z. Motilin and clinical application. Peptides 1997;18:593-608.

26. Mochiki E, Satoh M, Tamura T, et al. Exogenous motilin stimulates endogenous release of motilin through cholinergic muscarinic pathways in the dog. Gastroenterology 1996;111:1456-1464.

27. Mochiki E, Inui A, Satoh M, Mizumoto A, Itoh Z. Motilin is a biosignal controlling cyclic release of pancreatic polypeptide via the vagus in fasted dogs. Am J Physiol 1997;272(2 Pt 1):G224-G232.

28. Sarna S, Chey WY, Condon RE, Dodds WJ, Myers T, Chang TM Cause-and-effect relationship between motilin and migrating myoelectric complexes. Am J Physiol 1983;245:G277-G284.

29. Takeshita E, Matsuura B, Dong M, Miller LJ, Matsui H, Onji M. Molecular characterization and distribution of motilin family receptors in the human gastrointestinal tract. J Gastroenterol 2006;41: 223-230.

30. Mizumoto A, Sano I, Matsunaga Y, Yamamoto O, Itoh Z, Ohshima K. Mechanism of motilin-induced contractions in isolated perfused canine stomach. Gastroenterology 1993;105:425-432.

31. Van Assche G, Depoortere I, Thijs T, Janssens JJ, Peeters TL. Concentration-dependent stimulation of cholinergic motor nerves or smooth muscle by [Nle13] motilin in the isolated rabbit gastric antrum. Eur J Pharmacol 1997;337:267-274.

32. Chung SA, Valdez DT, Diamant NE. Adrenergic blockage does not restore the canine gastric migrating motor complex during vagal blockade. Gastroenterology 1992;103:1491-1497.

33. Tanaka T, Kendrick ML, Zyromski NJ, Meile T, Sarr MG. Vagal innervation modulates motor pattern but not initiation of canine gastric migrating motor complex. Am J Physiol Gastrointest Liver Physiol 2001;281:G283-G292.

34. Yoshida N, Mizumoto A, Iwanaga Y, Itoh Z. Effects of 5-hydroxytryptamine 3 receptor antagonists on gastrointestinal motor activity in conscious dogs. J Pharmacol Exp Ther 1991;256:272-278.

35. Haga N, Mizumoto A, Satoh M, et al. Role of endogenous 5-hydroxytryptamine in the regulation of gastric contractions by motilin in dogs. Am J Physiol 1996;270(1 Pt 1):G20-G28.

36. Wilmer A, Tack J, Coremans G, Janssens J, Peeters T, Vantrappen G. 5-hydroxytryptamine-3 receptors are involved in the initiation of gastric phase-3 motor activity in humans. Gastroenterology 1993; 105:773-780. 
37. Leslie RA. Comparative aspects of the area postrema: fine-structural considerations help to determine its function. Cell Mol Neurobiol 1986;6:95-120.

38. Poitras P, Steinbach JH, VanDeventer G, Code CF, Walsh JH. Motilin-independent ectopic fronts of the interdigestive myoelectric complex in dogs. Am J Physiol 1980;239:G215-G220.

39. Lee KY, Chang TM, Chey WY. Effect of rabbit antimotilin serum on myoelectric activity and plasma motilin concentration in fasting dog. Am J Physiol 1983;245:G547-G553.

40. Itoh Z, Aizawa I, Honda R, Takeuchi S, Mori K. Regular and irregular cycles of interdigestive contractions in the stomach. Am J Physiol 1980;238:G85-G90.

41. Itoh Z, Honda R, Aizawa I. Diurnal $\mathrm{pH}$ changes in duodenum of conscious dogs. Am J Physiol 1980;238:G91-G96.

42. Itoh Z, Takahashi I. Periodic contractions of the canine gallbladder during the interdigestive state. Am J Physiol 1981;240:G183-G189.

43. Ormsbee HS 3rd, Silber DA, Hardy FE Jr. Serotonin regulation of the canine migrating motor complex. J Pharmacol Exp Ther 1984; 231:436-440.

44. Gorard DA, Libby GW, Farthing MJ. 5-Hydroxytryptamine and human small intestinal motility: effect of inhibiting 5-hydroxytryptamine reuptake. Gut 1994;35:496-500.

45. Gershon MD, Drakontides AB, Ross LL. Serotonin: synthesis and release from the myenteric plexus of the mouse intestine. Science 1965;149:197-199.

46. Gershon MD. Nerves, reflexes, and the enteric nervous system: pathogenesis of the irritable bowel syndrome. J Clin Gastroenterol 2005;39(5 suppl 3):S184-S193.

47. Ahlman H, DeMagistris L, Zinner M, Jaffe BM. Release of immunoreactive serotonin into the lumen of the feline gut in response to vagal nerve stimulation. Science 1981;213:1254-1255.

48. Gronstad K, Dahlstrom A, Florence L, Zinner MJ, Ahlman J, Jaffe BM. Regulatory mechanisms in endoluminal release of serotonin and substance P from feline jejunum. Dig Dis Sci 1987;32:393-400.

49. Kellum J, McCabe M, Schneier J, Donowitz M. Neural control of acid-induced serotonin release from rabbit duodenum. Am J Physiol 1983;245:G824-G831.

50. Ferrara A, Zinner MJ, Jaffe BM. Intraluminal release of serotonin, substance $\mathrm{P}$, and gastrin in the canine small intestine. Dig Dis Sci 1987;32:289-294.

51. Larsson I. Studies on the extrinsic neural control of serotonin release from the small intestine. Acta Physiol Scand 1981;499(suppl):1-43.

52. Zinner MJ, Jaffe BM, DeMagistris L, Dahlstrom A, Ahlman H. Effect of cervical and thoracic vagal stimulation on luminal serotonin release and regional blood flow in cats. Gastroenterology 1982;82: 1403-1408.

53. Tsukamoto K, Ariga H, Mantyh C, et al. Luminally released serotonin stimulates colonic motility and accelerates colonic transit in rats. Am J Physiol Regul Integr Comp Physiol 2007;293:R64-R69.

54. Fujimiya M, Okumiya K, Kuwahara A. Immunoelectron microscopic study of the luminal release of serotonin from rat enterochromaffin cells induced by high intraluminal pressure. Histochem Cell Biol 1997;108:105-113.

55. Cooke HJ, Montakhab M, Wade PR, Wood JD. Transmural fluxes of 5-hydroxytryptamine in guinea pig ileum. Am J Physiol 1983;244: G421-G425.
56. Martel F, Monteiro R, Lemos C, Vieira-Coelho MA. In vitro and in vivo effect of fluoxetine on the permeability of $3 \mathrm{H}$-serotonin across rat intestine. Can J Physiol Pharmacol 2004;82:940-950.

57. Fukumoto S, Tatewaki M, Yamada T, et al. Short-chain fatty acids stimulate colonic transit via intraluminal 5-HT release in rats. Am J Physiol Regul Integr Comp Physiol 2003;284:R1269-R1276.

58. Foxx-Orenstein AE, Kuemmerle JF, Grider JR. Distinct 5-HT receptors mediate the peristaltic reflex induced by mucosal stimuli in human and guinea pig intestine. Gastroenterology 1996;111:12811290.

59. Bertrand PP, Kunze WA, Furness JB, Bornstein JC. The terminals of myenteric intrinsic primary afferent neurons of the guinea-pig ileum are excited by 5 -hydroxytryptamine acting at 5-hydroxytryptamine-3 receptors. Neuroscience 2000;101:459-469.

60. Hicks GA, Coldwell JR, Schindler M, et al. Excitation of rat colonic afferent fibres by 5-HT(3) receptors. J Physiol 2002;544(Pt 3):861869.

61. Nakajima H, Mochiki E, Zietlow A, Ludwig K, Takahashi T. Mechanism of interdigestive migrating motor complex in conscious dogs. J Gastroenterol 2010;45:506-514.

62. Glatzle J, Sternini C, Robin C, et al. Expression of 5- $\mathrm{HT}_{3}$ receptors in the rat gastrointestinal tract. Gastroenterology 2002;123:217-226.

63. Berthoud HR, Kressel M, Raybould HE, Neuhuber WL. Vagal sensors in the rat duodenal mucosa: distribution and structure as revealed by in vivo DiI-tracing. Anat Embryol (Berl) 1995;191:203212.

64. Tanaka T, Mizumoto A, Mochiki E, Haga N, Suzuki H, Itoh Z. Relationship between intraduodenal 5-hydroxytryptamine release and interdigestive contractions in dogs. J Smooth Muscle Res 2004;40: 75-84.

65. Kellum JM, Maxwell RJ, Potter J, Kummerle JF. Motilin's induction of phasic contractility in canine jejunum is mediated by the luminal release of serotonin. Surgery 1986;100:445-453.

66. Tougas G, Allescher HD, Dent J, Daniel EE. Sensory nerves of the intestines: role in control of pyloric region of dogs. Adv Exp Med Biol 1991;298:199-211.

67. Chen MH, Joffe SN, Magee DF, Murphy RF, Naruse S. Cyclic changes of plasma pancreatic polypeptide and pancreatic secretion in fasting dogs. J Physiol 1983;341:453-461.

68. DiMagno EP, Hendricks JC, Go VL, Dozois RR. Relationships among canine fasting pancreatic and biliary secretions, pancreatic duct pressure, and duodenal phase III motor activity - Boldyreff revisited. Dig Dis Sci 1979;24:689-693.

69. Mönnikes H, Tebbe JJ, Hildebrandt M, et al. Role of stress in functional gastrointestinal disorders. Evidence for stress-induced alterations in gastrointestinal motility and sensitivity. Dig Dis 2001;19: 201-211.

70. Feinle-Bisset C, Andrews JM. Treatment of functional dyspepsia. Curr Treat Options Gastroenterol 2003;6:289-297.

71. Holtmann G, Kutscher SU, Haag S, et al. Clinical presentation and personality factors are predictors of the response to treatment in patients with functional dyspepsia; a randomized, double-blind placebo-controlled crossover study. Dig Dis Sci 2004;49:672-679.

72. Barone FC, Deegan JF, Price WJ, Fowler PJ, Fondacaro JD, Ormsbee HS 3rd. Cold-restraint stress increases rat fecal pellet output and colonic transit. Am J Physiol 1990;258(3 Pt 1):G329-G337. 
73. Gue M, Junien JL, Bueno L. Conditioned emotional response in rats enhances colonic motility through the central release of corticotropin-releasing factor. Gastroenterology 1991;100:964-970.

74. Taché Y, Martinez V, Wang L, Million M. CRF1 receptor signaling pathways are involved in stress-related alterations of colonic function and viscerosensitivity: implications for irritable bowel syndrome. Br J Pharmacol 2004;141:1321-1330.

75. Martínez V, Wang L, Rivier J, Grigoriadis D, Taché Y. Central $\mathrm{CRF}$, urocortins and stress increase colonic transit via CRF1 receptors while activation of $\mathrm{CRF} 2$ receptors delays gastric transit in mice. J Physiol 2004;556:221-234.

76. Nakade Y, Tsuchida D, Fukuda H, Iwa M, Pappas TN, Takahashi T. Restraint stress delays solid gastric emptying via a central CRF and peripheral sympathetic neuron in rats. Am J Physiol Regul Integr Comp Physiol 2005;288:R427-R432.

77. Taché Y, Maeda-Hagiwara M, Turkelson CM. Central nervous system action of corticotropin-releasing factor to inhibit gastric emptying in rats. Am J Physiol 1987;253(2 Pt 1):G241-G245.

78. Broccardo M, Improta G. Pituitary-adrenal and vagus modulation of sauvagine- and CRF-induced inhibition of gastric emptying in rats. Eur J Pharmacol 1990;182:357-362.

79. Lenz HJ, Burlage M, Raedler A, Greten H. Central nervous system effects of corticotropin-releasing factor on gastrointestinal transit in the rat. Gastroenterology 1988;94:598-602.

80. Gué M, Bueno L. Diazepam and muscimol blockade of the gastrointestinal motor disturbances induced by acoustic stress in dogs. Eur J Pharmacol 1986;131:123-127.

81. Gue M, Fioramonti J, Frexinos J, Alvinerie M, Bueno L. Influence of acoustic stress by noise on gastrointestinal motility in dogs. Dig Dis Sci 1987;32:1411-1417.

82. Gue M, Honde C, Pascaud X, Junien JL, Alvinerie M, Bueno L. CNS blockade of acoustic stress-induced gastric motor inhibition by kappa-opiate agonists in dogs. Am J Physiol 1988;254(6 Pt 1):G802G807.

83. Taniguchi H, Imai K, Ludwig K, Takahashi T. Effects of acupuncture on stress-induced gastrointestinal dysmotility in conscious dogs. Medical Acupuncture 2012;24:43-49.

84. Vantrappen G, Janssens J, Hellemans J, Ghoos Y. The interdigestive motor complex of normal subjects and patients with bacterial overgrowth of the small intestine. J Clin Invest 1977;59:1158-1166.

85. Testoni PA, Bagnolo F, Bologna P, et al. Higher prevalence of Helicobacter pylori infection in dyspeptic patients who do not have gastric phase III of the migrating motor complex. Scand J Gastroenterol 1996;31:1063-1068.

86. Testoni PA, Bagnolo F. In dyspeptic patients without gastric phase III of the migrating motor complex, Helicobacter pylori eradication produces no short-term changes in interdigestive motility pattern. Scand J Gastroenterol 2000;35:808-813.

87. Tack J, Bisschops R, Sarnelli G. Pathophysiology and Treatment of Functional Dyspepsia. Gastroenterology 2004;127:1239-1255.

88. Quigley EM, Donovan JP, Lane MJ, Gallagher TF. Antroduodenal manometry. Usefulness and limitations as an outpatient study. Dig Dis Sci 1992;37:20-28.

89. Gu C, Ke M, Wang Z. Temporal and spatial relationship of pylorus to antroduodenal motility in functional dyspepsia. Chin Med J (Engl) 1998;111:906-909.

90. Kusano M, Sekiguchi T, Kawamura O, et al. Further classification of dysmotility-like dyspepsia by interdigestive gastroduodenal manometry and plasma motilin level. Am J Gastroenterol 1997;92:481484.

91. Kusano M, Sekiguchi T, Kawamura O, Kikuchi K, Nakamura K, Mori M. Disturbed initiation of gastric interdigestive migrating complexes despite high plasma motilin levels in patients with low gastric pH. Dig Dis Sci 1998;43:1697-1700.

92. Greydanus MP, Vassallo M, Camilleri M, Nelson DK, Hanson RB, Thomforde GM. Neurohormonal factors in functional dyspepsia: insights on pathophysiological mechanisms. Gastroenterology 1991; 100(5 Pt 1):1311-1318.

93. Holtmann G, Goebell H, Jockenhoevel F, Talley NJ. Altered vagal and intestinal mechanosensory function in chronic unexplained dyspepsia. Gut 1998;42:501-506. 